\title{
A Room-temperature Hydrogen Gas Sensor Using Palladium-decorated Single- Walled Carbon Nanotube/Si Heterojunction
}

\author{
Yong Gang DU *, Hai Xia ZHENG, Hao NI \\ College of Science, China University of Petroleum, Qingdao, Shandong 266580, People's Republic of China \\ cross $^{\text {ref }}$ http://dx.doi.org/10.5755/j01.ms.22.2.12925
}

Received 20 August 2015; accepted 28 February 2016

\begin{abstract}
We report a room-temperature (RT) hydrogen gas $\left(\mathrm{H}_{2}\right)$ sensor based on palladium-decorated single-walled carbon nanotube/Si (Pd-SWNTs/Si) heterojunction. The current-voltage (I-V) curves of the Pd-SWNTs/Si heterojunction in different concentrations of $\mathrm{H}_{2}$ were measured. The experimental results reveal that the Pd-SWNTs/Si heterojunction exhibits high $\mathrm{H}_{2}$ response. After exposure to $0.02 \%, 0.05 \%$, and $0.1 \% \mathrm{H}_{2}$ for $10 \mathrm{~min}$, the resistance of the heterojunction increases dramatically. The response is $122 \%, 269 \%$ and $457 \%$, respectively. A simple interfacial theory is used to understand the gas sensitivity results. This approach is a step toward future CNTs-based gas sensors for practical application.

Keywords: gas sensor, carbon nanotube, heterojunction.
\end{abstract}

\section{INTRODUCTION}

Due to its high efficiency, renewable properties, and for being environmentally friendly, hydrogen gas $\left(\mathrm{H}_{2}\right)$ provides an enormous potential solution to the current and future energy supply and environmental challenge [1]. However, $\mathrm{H}_{2}$ is a colorless and odorless gas, with a wide explosive concentration range $(4-75 \%)$ at standard atmospheric pressure. Therefore, to ensure the safety of its generation, transport and storage, an $\mathrm{H}_{2}$ sensor that can detect and monitor $\mathrm{H}_{2}$ leakage is required [2]. Various metal-oxide semiconductors, such as $\mathrm{SnO}_{2}$ [3], have been selected to fabricate $\mathrm{H}_{2}$ sensors, which require better performance at high temperatures, resulting in high power consumption and difficulty in integration. So, it is essential to select suitable materials for fabricating $\mathrm{H}_{2}$ sensors for detecting the content of hydrogen at room temperature (RT) in the development of a hydrogen energy industry [4].

Carbon nanotubes (CNTs) have attracted significant interests as a promising chemical sensing material because of their inherent properties such as its extremely small size, high strength, high electrical and thermal conductivity, and high specific surface area [5]. Recent studies show that CNTs-based gas sensor can effectively detect polar molecules at RT, such as ammonia gas $\left(\mathrm{NH}_{3}\right)$ and nitrogen dioxide $\left(\mathrm{NO}_{2}\right)$ because the electrical conductivity of CNTs changes drastically upon exposure to these gases $[6,7]$. However, CNTs are insensitive to most nonpolar molecules including $\mathrm{H}_{2}$. Pd is considered to be an attractive $\mathrm{H}_{2}$ sensing material because of its superior $\mathrm{H}_{2}$ solubility at $\mathrm{RT}$. In recent years, $\mathrm{Pd}$ as catalyst decorated on CNTs (Pd-CNTs) for $\mathrm{H}_{2}$ sensor have been reported, and most of them are Pd-CNTs resistance-type [8]. A typical Pd-CNTs resistance-type consists of one or several pairs of electrodes that make electrical contact with the Pd-CNTs film. A change in the electrical resistance of the Pd-CNTs film upon exposure to $\mathrm{H}_{2}$ is measured as the output signal [9]. The advantages of resistance-type $\mathrm{H}_{2}$ sensor include low power consumption and simple operation. However, the gas response of PdCNTs resistance-type $\mathrm{H}_{2}$ sensors is not high enough for excellent gas sensors.

In this paper, we fabricated Pd nanoparticles decorated single-walled carbon nanotube/Si (Pd-SWNTs/Si) heterojunction $\mathrm{H}_{2}$ sensor. It is found that $\mathrm{H}_{2}$ molecules have a dramatic effect on the current-voltage (I-V) characteristics of the Pd-SWNTs/Si heterojunction at RT. Upon exposure to $0.02 \%, 0.05 \%$ and $0.1 \% \mathrm{H}_{2}$ at $\mathrm{RT}$, the interface resistance of the heterojunction is found to dramatically increase to about $122 \%, 269 \%$ and $457 \%$. The results show that the heterojunction has very high $\mathrm{H}_{2}$ gas response than that of CNT-based resistance-type $\mathrm{H}_{2}$ sensors reported previously.

\section{MATERIALS AND EXPERIMENTS}

Carboxylic acid functionalized SWNTs (Length: $30 \mu \mathrm{m}$, -COOH content: 2.73 wt., purity: > $90 \%$ ) were purchased from the Xian Feng Nano Company and used without further purification. Palladium chloride $\left(\mathrm{PdCl}_{2}\right.$, purity: > $99.9 \%$ ) was purchased from Aladdin Inc. The mixed cellulose esters (MCE) filter membranes were purchased from Whatman Inc.

Pd-SWNTs was prepared according to a method reported previously $[10,11]$. Typically, $6 \mathrm{mg}$ of carboxylic acid functionalized SWNTs and $20 \mathrm{mg} \mathrm{PdCl}_{2}$ were added to $20 \mathrm{ml}$ of deionized water and sonicated for $60 \mathrm{~min}$. Subsequently, $5 \mathrm{ml}$ of aqueous solution of sodium borohydride $\left(\mathrm{NaBH}_{4}\right)(0.01 \mathrm{M})$ was added dropwise to the mixture as a reductant for $\mathrm{PdCl}_{2}$ for $20 \mathrm{~min}$ to obtain $\mathrm{Pd}$ SWNTs. Then, the aqueous suspension of the as-prepared Pd-SWNTs solution was magnetically stirred for two hours after adding $475 \mathrm{ml}$ deionized water. Lastly, a few drops of Triton X-100 surfactant were added to disperse further PdSWNTs into deionized water.

\footnotetext{
* Corresponding author. Tel.: +86-532-86981169;

fax: +386-532-86981169. E-mail address: duyg@upc.edu.cn (Y.G. Du)
} 
The Pd-SWNTs/Si heterojunctions were obtained by a filtration and transfer printing method [12]. Typically, $10 \mathrm{ml}$ of the as-prepared Pd-SWNTs solution was vacuum filtered through a mixed cellulose ester membrane and then a thin Pd-SWNTs film was attached on it. Both p-type and n-type $\mathrm{Si}$ wafers were used as substrates for transfer printing of the Pd-SWNTs films. The mixed cellulose ester membranes with Pd-SWNTs films on them were placed on the Si substrates. Then, a compressive force was applied on the mixed cellulose ester membranes during baking in an oven at $80{ }^{\circ} \mathrm{C}$ for two hours to stabilize the adhesion of the PdSWNTs film to the substrates. Finally, the mixed cellulose ester membranes were dissolved by acetone, thus the PdSWNTs/Si heterojunction were fabricated.

\section{EXPERIMENTAL RESULTS}

Fig. 1 shows the typical scanning electron microscopy (SEM) image of the as-prepared Pd-SWNTs film on Si substrate. As seen, the film is networks constituted by randomly oriented Pd-SWNTs bundles.

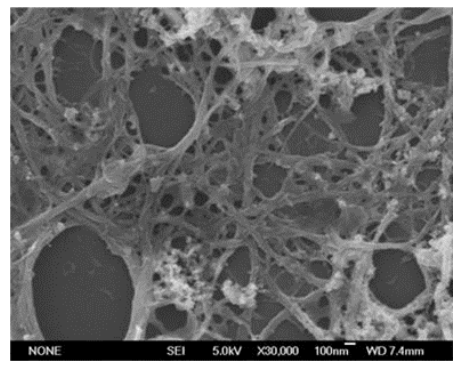

Fig. 1. SEM image of Pd decorated SWNTs film on Si substrate

The I-V curves of the Pd-SWNTs/p-Si and PdSWNTs/n-Si heterojunctions in the air are shown in Fig. 2. All $\mathrm{H}_{2}$ sensing experiments were investigated by exposing the heterojunctions to various concentrations $\mathrm{H}_{2}$. The gas concentration was obtained by injecting a required quantity of $\mathrm{H}_{2}$ gas into a homemade test chamber with the air. The $\mathrm{I}-\mathrm{V}$ characteristics of the Pd-SWNTs/Si heterojunctions were measured by using the two-probe method with a Keithley 2400 sourcemeter.

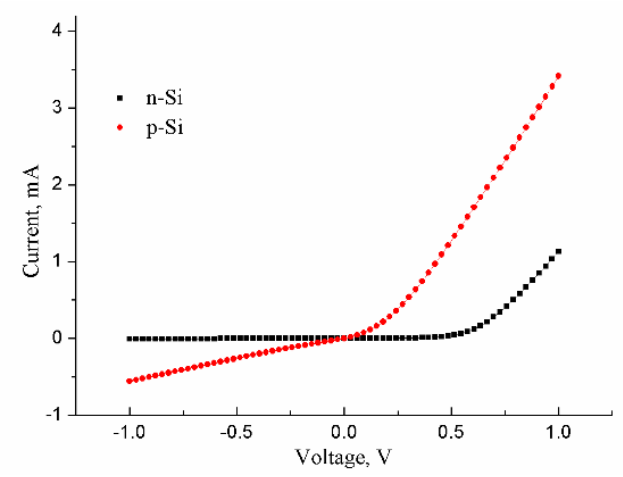

Fig. 2. The I-V curves of the Pd-SWNTs/n-Si and Pd-SWNTs/p-Si heterojunction in the air

As can be seen, the I-V curve of the Pd-SWNTs/n-Si heterojunction in the air shows a good rectifying behavior [13]. As can be seen, by contrast, the I-V curve of the PdSWNTs/p-Si heterojunction in the air shows a poor rectifying behavior with a big leakage current under reverse bias voltage [14]. The current rectification ratio at a bias voltage of $\pm 1 \mathrm{~V}$ of the Pd-SWCNT/n-Si heterojunction in the air is about 220 while the current rectification ratio of the Pd-SWCNT/n-Si heterojunction is only 6.

The semi-logarithm plots for the I-V curves of the PdSWNTs/p-Si and Pd-SWNTs/n-Si heterojunctions in the air, $0.02 \%, 0.05 \%$, and $0.1 \% \mathrm{H}_{2}$ are shown in Fig. 3 .

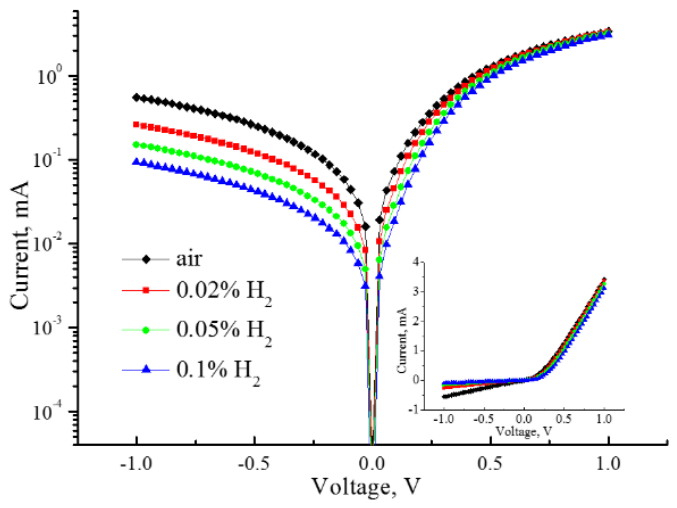

a

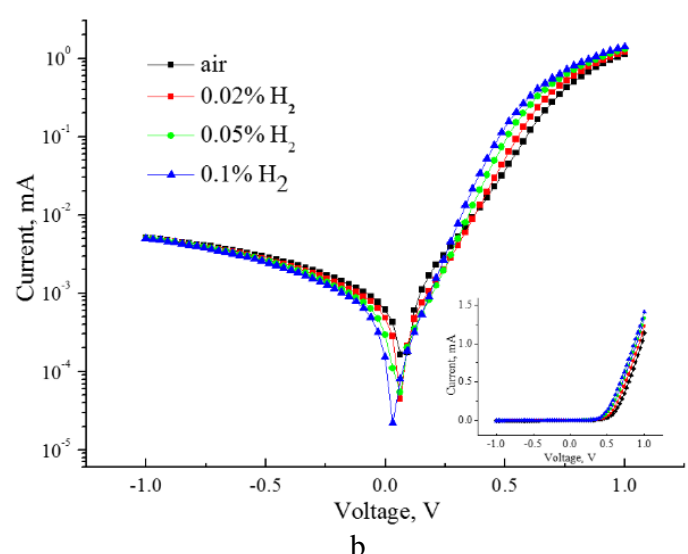

Fig. 3. Semi-logarithm plots of measured I-V curves of: a-the PdSWNTs/p-Si; b-Pd-SWNTS/n-Si heterojunctions in the air, $0.02 \%, 0.05 \%$ and $0.1 \% \mathrm{H}_{2}$. The insets show the I-V curves of the corresponding heterojunction

The insets show the I-V curves of the corresponding heterojunctions. As can be seen in Fig. 3 a, it is found that $\mathrm{H}_{2}$ has an obvious effect on the I-V curves of the PdSWNTs/p-Si heterojunction. When the Pd-SWNTs/p-Si heterojunction is exposed to $\mathrm{H}_{2}$, the currents decrease with increasing $\mathrm{H}_{2}$ concentration. Relatively, the change of the reverse current is higher than that of the forward current, leading a better rectifying behavior. The current rectification ratio at $\pm 1 \mathrm{~V}$ is 13,21 and 33 when the $\mathrm{Pd}-$ SWNTs/p-Si heterojunction is exposed to $0.02 \%, 0.05 \%$, and $0.1 \% \mathrm{H}_{2}$, respectively, at RT. Differently from the case of the Pd-SWNTs/p-Si heterojunction, as can be seen in Fig. 3 b, the reverse current decreases when the $\mathrm{Pd}$ SWNTs/n-Si heterojunction is exposed to $\mathrm{H}_{2}$ while the forward current does not always increase or decrease with increasing $\mathrm{H}_{2}$ concentration. These phenomena could be understood by the interfacial effects between Pd-SWNT film and $\mathrm{Si}$ substrate. When the Pd-SWNTs/Si heterojunction are exposed to $\mathrm{H}_{2}$, Pd nanoparticle absorbs $\mathrm{H}_{2}$ molecules, which will lower the work function of $\mathrm{Pd}$ nanoparticle, leading to the enhanced Fermi level of Pd-SWNTs film. For the Pd-SWNTs/n-Si (p-Si) heterojunction, the energy difference between Fermi levels of the $\mathrm{n}-\mathrm{Si}(\mathrm{p}-\mathrm{Si})$ and the Pd-SWNTs will decrease (increase). Thus, the potential barrier height between the Pd- 
SWNTs film and the n-Si (p-Si) substrate will decrease (increase) [13, 14]. According to the reference [15], this leads to the increase (decrease) of the currents. At the same time, the electrons from Pd nanoparticles trap and neutralize the hole-carries in SWNTs, which increases the resistance of Pd-SWNTs film and the series resistance of the PdSWNTs/p-Si heterojunction [16]. That is, when the PdSWNTs/p-Si heterojunction is exposed to $\mathrm{H}_{2}$, the change of barrier height leads to a decrease in the current, and so does the change of series resistance, which is always synergistic in the case of Pd-SWNTs/p-Si heterojunction. However, it is always adverse in the case of the Pd-SWNTs/n-Si heterojunction. When the Pd-SWNTs/n-Si heterojunction is exposed to $\mathrm{H}_{2}$, the change of barrier height leads to an increase in the current, but the change of series resistance leads to a decrease in the current [16]. The current of the Pd$\mathrm{SWNTs}_{2} / \mathrm{n}$-Si heterojunction will increase if the effect of barrier height is dominant. Meanwhile, the current will decrease if the effect of series resistance is dominant, as shown in Fig. 3 b.

Compared to the Pd-SWNTs/p-Si heterojunction, the currents of the Pd-SWNTs/n-Si heterojunction show smaller changes, indicating the former have a higher $\mathrm{H}_{2}$ response. So we selected the $\mathrm{Pd}-\mathrm{SWNTs} / \mathrm{p}-\mathrm{Si}$ heterojunction to examine further the dynamic sensing performance. The dynamic responses of the Pd-SWNTs/p-Si heterojunction at a reverse bias voltage of $-1 \mathrm{~V}$ is shown in Fig. 4 . The response is defined as:

$\Delta R / R_{\text {air }}=\left(R_{H_{2}}-R_{\text {air }}\right) / R_{\text {air }}$,

where $R_{\text {air }}$ and $R_{H^{2}}$ are the resistances of the sensor before and after exposure to $\mathrm{H}_{2}$, respectively. As can be seen in Fig. 4, after exposure to $0.02 \%, 0.05 \%$, and $0.1 \% \mathrm{H}_{2}$ for $10 \mathrm{~min}$, the resistance of the heterojunction increases dramatically. The response is $122 \%, 269 \%$ and $457 \%$, respectively. The Pd-SWNTs/p-Si heterojunction shows very high $\mathrm{H}_{2}$ response, which is superior to those of CNTbased resistance-type $\mathrm{H}_{2}$ sensors reported previously. For example, Aguilar et al. got a response of $40 \%$ to $3.3 \% \mathrm{H}_{2}$ with Pd-SWNTs at RT and Gong et al. got a response of $115 \%$ to $0.15 \% \mathrm{H}_{2}$ with $\mathrm{SWNTs} / \mathrm{SnO}_{2}$ nano composites at $200{ }^{\circ} \mathrm{C}[17,18]$.

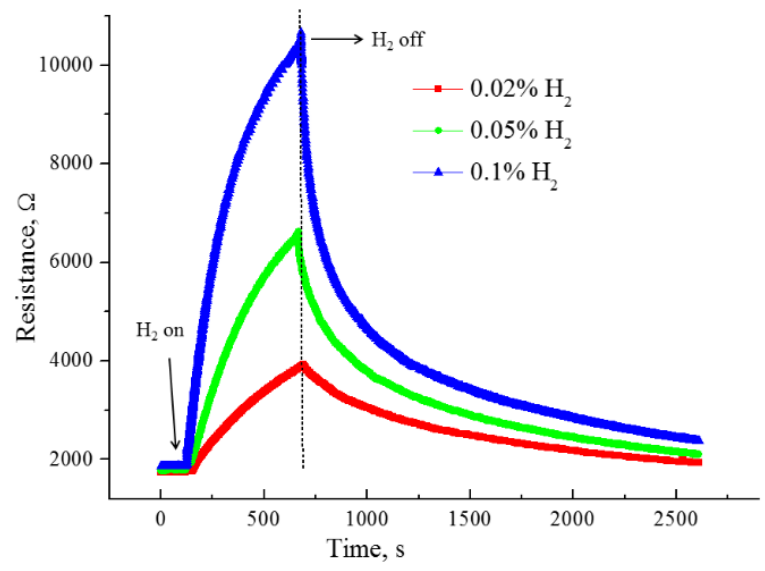

Fig. 4. Dynamic responses to $0.02 \%, 0.05 \%$ and $0.1 \% \mathrm{H}_{2}$ of thePd-SWNTs/p-Si heterojunction at a reverse bias voltage of $-1 \mathrm{~V}$ at room temperature

\section{CONCLUSIONS}

In conclusion, we have developed high response room temperature $\mathrm{H}_{2}$ gas sensors based on the Pd-SWNTs/Si heterojunction. The response is $122 \%, 269 \%$ and $457 \%$ after exposure to $0.02 \%, 0.05 \%$, and $0.1 \% \mathrm{H}_{2}$ for $10 \mathrm{~min}$, respectively. This will facilitate the development of a new type of sensing platform.

\section{Acknowledgement}

The authors gratefully acknowledge financial support by the Fundamental Research Funds for the Central Universities (15CX02073A), the Natural Science Foundation of Shandong Province (ZR2015AQ012).

\section{REFERENCES}

1. Rumiche, F., Wang, H.H., Indacochea, J.E. Development of a Fast-Response/High-Sensitivity Double Wall Carbon Nanotube Nanostructured Hydrogen Sensor Sensors and Actuators B: Chemical 163 2012: pp. 97-106. http://dx.doi.org/10.1016/j.snb.2012.01.015

2. Song, H.D., Cho, S.H., Jeon, I., Kee, C.D. A Sensing Medium Exchangeable Hydrogen Sensor Using Lamb Waves Sensors and Actuators B: Chemical $162(1)$ 2012: pp. $348-352$.

http://dx.doi.org/10.1016/j.snb.2011.12.095

3. Wang, B., Zhu, L.F., Yang, Y.H., Xu, N.S., Yang, G.W. Fabrication of a $\mathrm{SnO}_{2}$ Nanowire Gas Sensor and Sensor Performance for Hydrogen The Journal of Physical Chemistry C 112 (17) 2008: pp. 6643-6647.

4. Lin, T.C., Huang, B.R. Palladium Nanoparticles Modified Carbon Nanotube/Nickel Composite Rods (Pd/CNT/Ni) for Hydrogen Sensing Sensors and Actuators B: Chemical 162 (1) 2012: pp. $108-113$.

5. Fam, D.W.H., $\quad$ Palaniappan, A., $\quad$ Tok, A.I.Y., Liedberg, B., Moochhala, S.M. A Review on Technological Aspects Influencing Commercialization of Carbon Nanotube Sensors Sensors and Actuators B: Chemical 157 (1) 2011: pp. 1-7.

6. Peng, N., Zhang, Q., Chow, C.L., Tan, O.K., Marzari, N. Sensing Mechanisms for Carbon Nanotube Based $\mathrm{NH}_{3}$ Gas Detection Nano letters 9 (4) 2009: pp. 1626-1630. http://dx.doi.org/10.1021/n1803930w

7. Li, J., Lu, Y., Ye, Q., Cinke, M., Han, J., Meyyappan, M. Carbon Nanotube Sensors for Gas and Organic Vapor Detection Nano Letters 3 (7) 2003: pp. 929-933.

8. Mubeen, S., Zhang, T., Yoo, B., Deshusses, M.A., Myung, N.V. Palladium Nanoparticles Decorated SingleWalled Carbon Nanotube Hydrogen Sensor The Journal of Physical Chemistry C 111 (17) 2007: pp. 6321-6327.

http://dx.doi.org/10.1021/jp067716m

9. Lee, J.H., Kang, W.S., Najeeb, C.K., Choi, B.S., Choi, S.W., Lee, H.J., Lee, S.S., Kim, J.H. A Hydrogen Gas Sensor Using Single-Walled Carbon Nanotube LangmuirBlodgett Films Decorated with Palladium Nanoparticles Sensors and Actuators B: Chemical 188 (1) 2013: pp. $169-175$.

10. Zilli, D., Bonelli, P.R., Cukierman, A.L. Room Temperature Hydrogen Gas Sensor Nanocomposite Based on Pd-Decorated Multi-Walled Carbon Nanotubes Thin Films Sensors and Actuators B: Chemical 157 (1) 2011: pp. $169-176$.

http://dx.doi.org/10.1016/j.snb.2011.03.045 
11. Kamalakannan, R., Kamruddin, M., Tyagi, A.K., Karthika, S. Pd Decorated Few Walled Carbon Nanotube Networks for Room Temperature Hydrogen Sensor Applications Nanoscience, Engineering and Technology (ICONSET) 2011 International Conference on. IEEE 2011: pp. 559-561.

12. Jia, Y., Li, P.X., Wei, J.Q., Cao, A.Y., Wang, K.L., Li, C.L., Zhuang, D.M., Zhu, H.W., Wu, D.H. Carbon Nanotube Films By Filtration for Nanotube-Silicon Heterojunction Solar Cells Materials Research Bulletin 45 (10) 2010: pp. $1401-1405$. http://dx.doi.org/10.1016/j.materresbull.2010.06.045

13. Jia, Y., Li, P.X., Gui, X.C., Wei, J.Q., Wang, K.L., Zhu, H.W. Encapsulated Carbon Nanotube-Oxide-Silicon Solar Cells with Stable $10 \%$ Efficiency Applied Physics Letters 98 (13) 2011: pp. 133115-133115. http://dx.doi.org/10.1063/1.3573829

14. Kawano, T., Christensen, D., Chen, S., Cho, C.Y., Lin, L.W. Formation and Characterization of Silicon/Carbon Nanotube/Silicon Heterojunctions by Local Synthesis and Assembly Applied Physics Letters 89 (16) 2006: pp. $163510-163510$.
15. Behnam, A., Radhakrishna, N.A., Wu, Z.C., Ural, A. Electronic Properties of Metal-Semiconductor and MetalOxide-Semiconductor Structures Composed of Carbon Nanotube Film on Silicon Applied Physics Letters 97 (23) 2010: pp. 233105-1-233105-3.

16. Du, Y.G., Xue, Q.Z., Zhang, Z.Y., Xia, F.J., Liu, Z.L., Xing, W. Enhanced Hydrogen Gas Response of $\mathrm{Pd}$ Nanoparticles-Decorated Single Walled Carbon Nanotube film/Sio2/Si Heterostructure AIP Advances 5 (2) 2015: pp. 027136-1 - 027136-9.

17. García-Aguilar, J., Miguel-García, I., BerenguerMurcia, A., Cazorla-Amorós, D. Single wall Carbon Nanotubes Loaded With Pd And Nipd Nanoparticles for $\mathrm{H}_{2}$ Sensing at Room Temperature Carbon 66 2014: pp. 599-611.

18. Gong, J., Sun, J., Chen, Q. Micromachined Sol-Gel Carbon Nanotube/ $\mathrm{SnO}_{2}$ Nanocomposite Hydrogen Sensor Sensors and Actuators B: Chemical 130 (2) 2008: pp. 829-835. http://dx.doi.org/10.1016/j.snb.2007.10.051 